\title{
AREA-WIDE INTEGRATED MANAGEMENT OF A Glossina palpalis gambiensis POPULATION FROM THE NIAYES AREA OF SENEGAL: A REVIEW OF OPERATIONAL RESEARCH IN SUPPORT OF A PHASED CONDITIONAL APPROACH
}

\author{
M. J. B. VREYSEN ${ }^{1}$, M. T. SECK ${ }^{2}$, B. SALL ${ }^{3}$, A. G. MBAYE ${ }^{4}$, \\ M. BASSENE 2 , A. G. FALL ${ }^{2}$, M. LO ${ }^{3}$ AND J. BOUYER ${ }^{1,2,5,6}$ \\ ${ }^{1}$ Insect Pest Control Laboratory, Joint FAO/IAEA Programme of Nuclear \\ Techniques in Food and Agriculture, A-1400, Vienna, Austria; \\ M.Vreysen@iaea.org \\ ${ }^{2}$ Institut Sénégalais de Recherches Agricoles, Laboratoire National d'Elevage et de \\ Recherches Vétérinaires, BP 2057, Dakar - Hann, Sénégal \\ ${ }^{3}$ Direction des Services Vétérinaires, BP 45 677, Dakar, Sénégal \\ ${ }^{4}$ Services Régionales de l'Elevage de Dakar \\ ${ }^{5}$ Unité Mixte de Recherche INTERTRYP, Centre de Coopération Internationale en \\ Recherche Agronomique pour le Développement (CIRAD), 34398, Montpellier, \\ France \\ ${ }^{6}$ Unité Mixte de Recherche CMAEE, CIRAD, 34398, Montpellier, France
}

\begin{abstract}
SUMMARY
In 2005, the Government of Senegal initiated a project entitled "Projet de lutte contre les glossines dans les Niayes" (Tsetse control project in the Niayes) with the aim of creating a zone free of Glossina palpalis gambiensis in that area. The project received technical and financial support from the International Atomic Energy Agency (IAEA), the Food and Agriculture Organization of the United Nations (FAO), the Centre de Coopération Internationale en Recherche Agronomique pour le Développement (CIRAD) and the US Department of State through the Peaceful Uses Initiative (PUI). It was implemented in the context of the Pan African Tsetse and Trypanosomosis Eradication Campaign (PATTEC) following a phased conditional approach (PCA) that entails implementation in distinct phases, in which support to the next phase is conditional upon completion of all (or at least the majority of) activities in the previous phase. In the case of the tsetse project in Senegal, the PCA consisted of 4 phases: (1) commitment of all stakeholders and training, (2) baseline data collection, feasibility studies and strategy development, (3) preparatory preoperational activities and (4) operational activities. This paper provides an overview of the main activities that were carried out within each phase, with emphasis on the operational research carried out in phases 2
\end{abstract}

J. Hendrichs, R. Pereira and M. J. B. Vreysen (eds.), Area-Wide Integrated Pest Management: Development and Field Application, pp. 275-303. CRC Press, Boca Raton, Florida, USA. (C) 2021 IAEA 
and 3, that was instrumental in guiding the project's decision-making. Activities of phase 2 focused on the collection of entomological, veterinary, socio-economic and environmental baseline data, and a population genetics study that proved the isolated character of the G. p. gambiensis population of the Niayes. These data enabled the tsetse-infested area to be delimited to $1000 \mathrm{~km}^{2}$, the impact of animal trypanosomosis on the farmers' welfare to be quantified (annual benefits of 2 million Euro in the tsetse-infested zone), and the formulation of an area-wide integrated pest management (AW-IPM) strategy that included a sterile insect (SIT) component to eradicate the isolated tsetse populations from the Niayes. In view of the extreme fragmentation of the remaining favourable habitat of the Niayes and the high human population density (peri-urban area), which excluded the possibility of using the Sequential Aerosol Technique, the IPM strategy that was selected comprised the suppression of the tsetse population with insecticide-impregnated traps/targets and the use of "pour-on" for cattle, followed by the release of sterile males to eliminate the remaining relic pockets. During phase 3, the pre-operational phase, a series of activities were carried out that were needed to implement the operational phase. These included the establishment of a colony of tsetse originating from the target area in Senegal, competitiveness studies between the sterile flies and those from the target area, development of transport methods for long-distance shipments of sterile male pupae, competitiveness of the sterile male flies after release in the target area, development of aerial release methods (including a new chilled adult release system) and development of a Maxent-based distribution model to guide the suppression, sterile male releases and monitoring of the eradication campaign. To be able to properly manage the eradication campaign in different phases, the entire target area was divided into 3 operational blocks. This paper demonstrates how, during the operational phase, scientific principles continued to guide the implementation process. The results to date are encouraging, i.e. the deployment of 269 insecticide-impregnated Vavoua traps in favourable habitat of Block 1 reduced the apparent density of the G. p. gambiensis population significantly (from 0.42 (SD 0.39) to 0.04 (SD 0.11) flies/trap/day). This was followed by the aerial release of sterile males that reduced the apparent density to zero after six months of releases. The last wild fly was trapped on August 9, 2012 in Block 1. In Block 2, during the suppression, the apparent fly density dropped from 1.24 (SD 1.23) to 0.005 (SD 0.017) flies/trap/day. Sterile male releases were initiated in February 2014 and expanded to cover the entire Block 2 in January 2015. The apparent fly density has so far been reduced to $<0.001$ fly per trap per day until the end of 2018 and releases are still ongoing. The results of the campaign are discussed with respect to the "adaptive management approach" used, which was deemed critical for the success of the campaign.

Key Words: African animal trypanosomosis, Trypanosoma vivax, Trypanosoma congolense, Trypanosoma brucei, nagana, livestock, Sterile Insect Technique, SIT, vector control, elimination, tsetse flies, integrated vector management, adaptive management

\section{THE TSETSE AND TRYPANOSOMOSIS PROBLEM IN THE NIAYES AND THE POLITICAL WILL TO FIND A SUSTAINABLE SOLUTION}

In the sub-humid savannah of West Africa, riverine tsetse species such as Glossina palpalis gambiensis (Vanderplank 1949) inhabit riparian forests where they are major vectors of African animal trypanosomosis (AAT) or nagana (Bouyer et al. 2006; Guerrini et al. 2008) and human African trypanosomosis (HAT) or sleeping sickness (Camara et al. 2006). In Senegal, as in other parts of West Africa, AAT is a major obstacle to the development of more efficient and sustainable livestock production (Itard et al. 2003) and the presence of tsetse flies is considered a major cause of hunger and poverty (Feldmann et al. 2021).Glossina p. gambiensis normally thrives in areas that receive a minimum of $600 \mathrm{~mm}$ annual rainfall (Brunhes et al. 1998), but in western Senegal, annual precipitation is limited to $400-500 \mathrm{~mm}$. Here, G. $p$. gambiensis populations are mainly confined to a specific ecosystem called the "Niayes" (Morel and Touré 1967; Touré 1971, 1973, 1974) that are situated around Dakar. These habitats are characterized by remnants of Guinean forests that are located in low-lying inter-dune depressions that are periodically or permanently flooded. However, in the last decades, these habitats have been drastically changed 
due to human intrusion. The second similar but drier ecosystem, "La Petite Côte", is situated south of Dakar and extends along the Atlantic coast towards Joal and the Sine Saloum River (Fig. 1).

In the Niayes, temperature is lower and rainfall higher as compared with the interior of the country, and these conditions facilitate intensive cropping and cattle production even during the dry season. Horses are present in high numbers and are mainly used for the transport of food crops. The bites from tsetse flies pose a continuous nuisance for human populations, especially in Sebikotane and Pout. In addition, the flies seem to have adapted to peri-urban, densely populated areas such as the "Parc de Hann", located in the city centre of Dakar.

The G. p. gambiensis populations that inhabited the Niayes and La Petite Côte belonged to one of the most north-western distributions of the tsetse belt in West Africa (Fig. 1). In 2007, a parasitological and serological survey of resident cattle revealed the seriousness of the tsetse and trypanosomosis problems in the area with AAT herd prevalence rates of 10-90\% (Baba Sall, unpublished data). This survey showed that Trypanosoma vivax Ziemann was the most prevalent species, followed by $T$. congolense Broden. However, the parasitological prevalence may be grossly underestimated, due to the poor sensitivity of the buffy coat technique that was used (Pinchbeck et al. 2008).

In the 1970 s, the first attempt was made to eliminate G. p. gambiensis populations from more than $150 \mathrm{~km}$ of linear habitat in the Niayes, using selective bush clearing and residual ground spraying with dieldrin. Although no tsetse flies were detected after the campaign (Toure 1973), they reappeared in the 1980s, necessitating a second campaign combining insecticide spraying with the deployment of traps and insecticide-impregnated screens. The tsetse problem seemed to have disappeared until in 1998 flies were again detected (Baba Sall, unpublished data).

Staff of the Direction de l'Elevage (DIREL) (now called Direction des Services Vétérinaires (DSV)) and the Institut Sénégalais de Recherches Agricoles (ISRA), in collaboration with the Joint FAO/IAEA Division of Nuclear Techniques in Food and Agriculture (the Food and Agriculture Organization of the United Nations (FAO), the International Atomic Energy Agency (IAEA)) and the IAEA's Department of Technical Cooperation, carried out more extensive surveys in 2002-2003. These surveys confirmed the presence of G. p. gambiensis and in view of the isolated nature of the Niayes population (Solano et al. 2010) it is highly likely that the resurgence of the tsetse fly population can be attributed to a population build-up from small residual pockets inside the Niayes, rather than to reinvasion from the main tsetse belt of the Sine Saloum region that is located more than $100 \mathrm{~km}$ southeast of Dakar (S. Leak, unpublished reports to the IAEA; Baba Sall, unpublished data).

Following confirmation of G. p. gambiensis presence in the Niayes, the DSV and FAO/IAEA initiated a tsetse control campaign that officially started in 2005. Entitled "Projet de lutte contre les glossines dans les Niayes" (Tsetse control project in the Niayes), it was mainly funded and implemented by the DSV of the Ministry of Livestock and Animal Production and ISRA of the Ministry of Agriculture and Rural Equipment. 


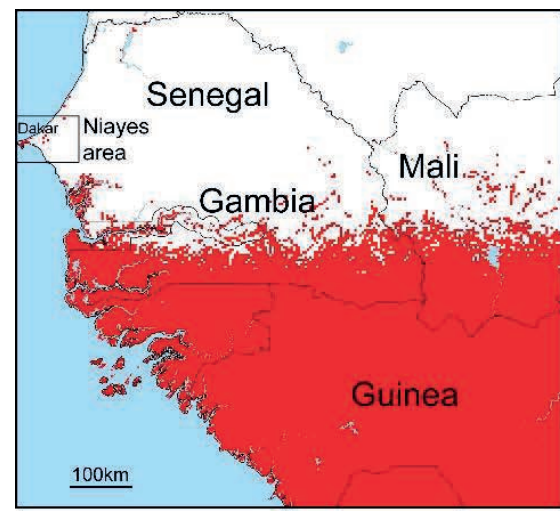

Senegal

Legend

Field surveys

O Learning site

$\diamond \quad$ Validation site

Habitat suitabilty for $G$. palpalis gambiensis

Not suitable

Suitable

Suitable but degraded

Wet areas

Niayes area

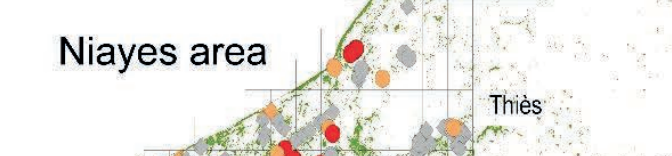

Dakar

Petite côte

Figure 1. Map top left: Distribution of Glossina palpalis gambiensis in West Africa and location of the Niayes area around Dakar in Senegal. The red area represents suitable habitats predicted from a Maxent model. Map right: The project area indicating the suitability of the vegetation for harbouring G. p. gambiensis after a phytosociological study, and the "wet areas" as obtained from a supervised classification (modified after Bouyer et al. 2010, 2015b). 
The project received technical and financial support from the IAEA, the FAO, the Centre de Coopération Internationale en Recherche Agronomique pour le Développement (CIRAD), and the US Department of State through the Peaceful Uses Initiative (PUI). The Centre International de Recherche-Développement sur l'Elevage en zone Sub-humide (CIRDES), Burkina Faso, the Slovak Academy of Sciences (SAS), Slovakia, and l'Institut de Recherche pour le Développement (IRD), France, were other full- or part-time partners in the project. The project was implemented in the context of the Pan African Tsetse and Trypanosomosis Eradication Campaign (PATTEC), a political initiative of the African Heads of State that called for increased efforts to better manage the tsetse and trypanosomosis problem on the African continent (PATTEC 2019).

\section{PHASED CONDITIONAL APPROACH}

From the onset, it was decided that the project would be implemented following a phased conditional approach (PCA), whereby project implementation follows distinct phases and in which support to the next phase is conditional upon completion of all (or at least the majority of) activities in the previous phase (Feldmann et al. 2018). Whereas the diverse phases of the PCA might differ with the target pest species, or if a suppression rather than an eradication strategy is selected (Hendrichs et al. 2021), the PCA consisted of 4 phases for the tsetse project in Senegal, i.e. (1) commitment of all stakeholders and training, (2) baseline data collection and feasibility studies, (3) pre-operational activities and (4) operational activities.

\subsection{Phase 1: Stakeholder Commitment and Training}

After the FAO/IAEA-supported surveys of 2002-2003, discussions within and between the Government of Senegal and the FAO/IAEA culminated in the submission of an official request by the Government of Senegal to the IAEA for technical and financial support. A technical cooperation project entitled "Feasibility Study to Create a Tsetse-free Zone Using the Sterile Insect Technique" was approved in 2005, which provided substantial support to phase 1 of the PCA.

The commitment of the Government was evidenced by the involvement of various Ministries in the project, i.e. the DSV of the Ministry of Livestock and Animal Production took responsibility for coordinating and implementing the project, the ISRA of the Ministry of Agriculture and Rural Equipment was given responsibility for operating the insectary/sterile male emergence and dispersal centre in Dakar and to guide the operational research that accompanied the project, and the Ministry of Environment and Sustainable Development provided the license to operate the project as it was considered environment-friendly.

Initially, training of essential project staff was emphasized, and a total of 16 veterinary field staff received training in tsetse biology, baseline data collection and control. This was a crucial step for the smooth implementation of the project in view of the limited experience of the field and insectary staff with tsetse flies, due to its absence from the Niayes for almost 20 years. 


\subsection{Phase 2: Collection of Baseline Data, Feasibility Studies and Strategy Development (2007-2010)}

The importance of the availability of relevant baseline data (phase 2) cannot be overemphasized, as an appropriate control strategy cannot be developed without such detailed and accurate data. Data were required on the geographic distribution of the target tsetse population, their spatial and temporal dynamics, their spatial occupation of the habitat, their genetic profile, the correlation between tsetse presence/density and the parasitological and serological disease prevalence, the socio-economic impact of AAT on the farming community and the potential impact of the selected strategy on the environment (Fig. 2).

At the onset of the project, only limited data was available; therefore, during the first four years, all efforts were focused on collecting these data as part of a feasibility study. The data collected greatly assisted the decision-making process for selecting an appropriate strategy to sustainably manage the tsetse and trypanosomosis problem in the Niayes (Vreysen et al. 2007). The baseline data also enabled accurate monitoring of the operational eradication phase and continuous assessment of the progress made (Leak et al. 2008; Vreysen 2021).

The feasibility study was initiated with the development of a specific entomological sampling protocol aimed at accurately defining the distribution of the G. p. gambiensis populations in the Niayes and La Petite Côte. To enable the practical implementation of the protocol, a $5 \times 5 \mathrm{~km}$ grid (286 cells) was superimposed over the entire initially defined project area of $7150 \mathrm{~km}^{2}$ to facilitate the field sampling procedures (Leak et al. 2008) (Figs. 1 and 2). Spatial analytical tools were used to facilitate a preliminary phytosociological census that identified eight different types of habitat suitable to harbour G. p. gambiensis, which were denominated "wet areas" (Fig. 1).

In early 2009, 683 unbaited Vavoua traps Laveissière and Grébaut 1990) were strategically deployed in the area and the trapping data indicated that tsetse flies were present in 21 grid cells representing an area of $525 \mathrm{~km}^{2}$. In the area of zero catches adjacent to the infested area ( 84 grid cells or $2100 \mathrm{~km}^{2}$ ), a mathematical model was used to assess the risk that flies were present despite a sequence of zero catches (Barclay and Hargrove 2005; Bouyer et al. 2010).

The analysis showed a risk of tsetse presence $>0.05$ in 16 grid cells or $400 \mathrm{~km}^{2}$ which represented $19 \%$ of the area, which was therefore considered potentially infested and included in the target area. The remote sensing analysis identified 285 $\mathrm{km}^{2}$ as wet areas, which comprised only $4 \%$ of the total project area of $7150 \mathrm{~km}^{2}$, whereas the mathematical model provided an efficient method to improve the accuracy and the robustness of the sampling protocol (Bouyer et al. 2010). Thus, the total area that could be considered as potentially infested with tsetse flies and that could be subjected to the control effort was estimated at approximately $1000 \mathrm{~km}^{2}$.

The entomological baseline data survey already indicated a high probability that the G. p. gambiensis populations of the Niayes were isolated from the remainder of the tsetse belt in the south-eastern part of Senegal. This assumption was mainly based on the absence of tsetse fly captures in La Petite Côte and the lack of any suitable tsetse habitat between the Niayes and the Sine Saloum, the nearest tsetse-infested area in the southeast. 


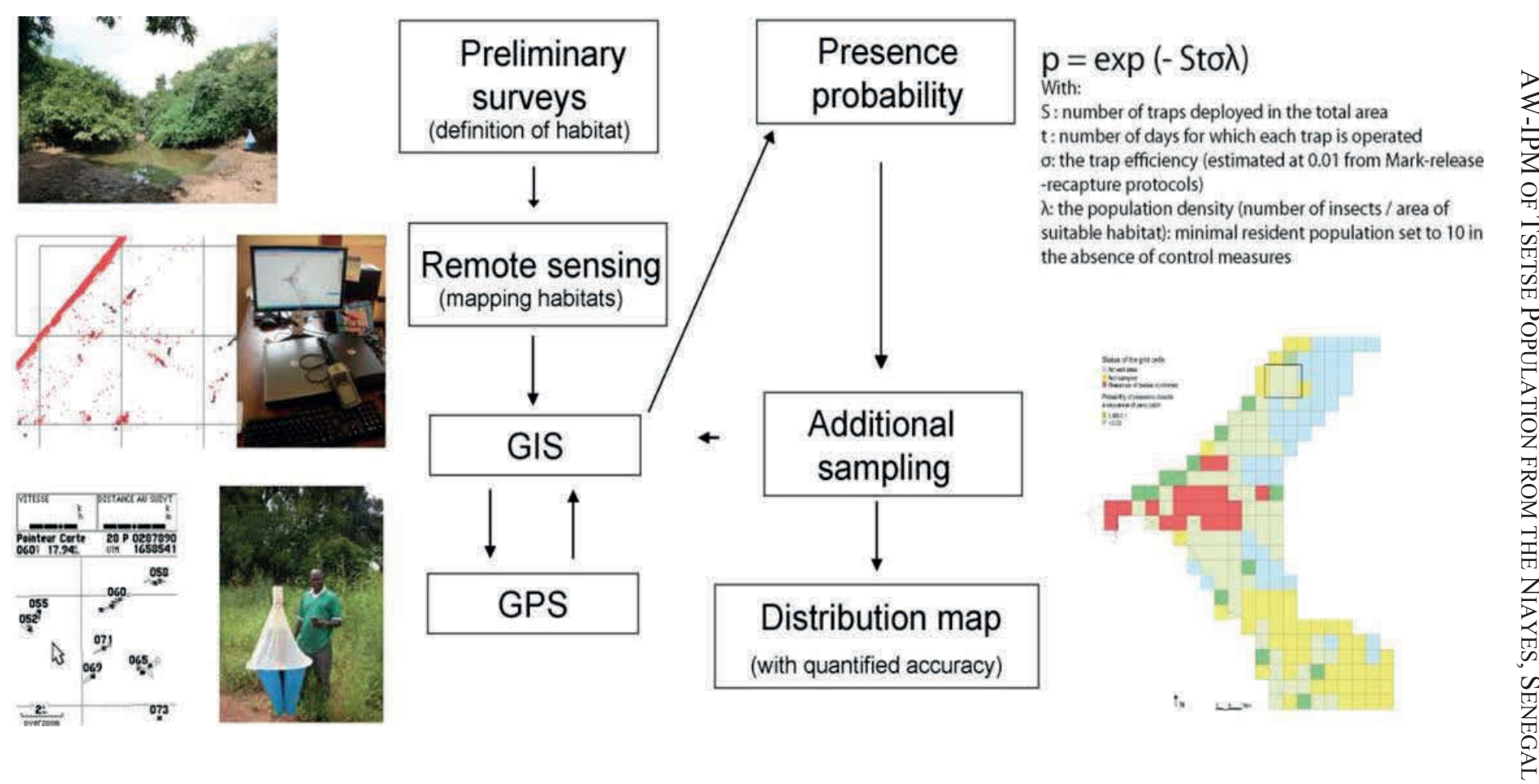

Figure 2. Sampling strategy used in the Niayes of Senegal to delimit the target population of G. p. gambiensis (modified from Bouyer et al. 2010). 
To confirm this assumption, the genetic differentiation between the G. $p$. gambiensis populations from the Niayes and those from the south-eastern tsetse belt (Missira) was assessed. Using microsatellite DNA, mitochondrial COI DNA and geometric morphometrics of the wings of 153 individuals, complete genetic isolation of the G. p. gambiensis populations of the Niayes was confirmed. In addition, the $G$. p. gambiensis tsetse population from the Parc de Hann in Dakar proved to be isolated from other populations in the Niayes (Solano et al. 2010).

A third study focused on the parasitological and serological prevalence of AAT in cattle residing inside and outside the tsetse-infested areas of the Niayes. Before any control efforts were implemented, a mean parasitological prevalence of $2.4 \%$ was detected at the herd level in the tsetse-infested area, whereas serological prevalences of 28.7, 4.4, and $0.3 \%$ were obtained for T. vivax, T. congolense and T. brucei brucei Plimmer and Bradford, respectively (Seck et al. 2010). Moreover, the observed risk of cattle becoming infected with $T$. congolense and $T$. vivax was 3 times higher in the tsetse-infested as compared with the assumed tsetse-free areas. Furthermore, AAT prevalence decreased significantly with distance from the nearest tsetse sampled, indicating that cyclical transmission of trypanosomes by tsetse flies predominated over any potential mechanical transmission by other biting flies present in the area (Seck et al. 2010).

In addition to these studies, a socio-economic study was carried out to assess potential benefits from the sustainable removal of G. p. gambiensis from the Niayes. The study identified three main cattle farming systems, i.e. (1) a traditional system using trypano-tolerant cattle, and (2) two "improved" systems using more productive cattle breeds for milk and meat production. Herd size in improved farming systems was $45 \%$ lower and annual cattle sales amounted to $€ 250$ per head as compared with $€ 74$ per head in the traditional farming system. Tsetse distribution significantly impacted the frequency of occurrence of these farming systems with $34 \%$ and $6 \%$ of farmers owning improved breeds in the tsetse-free and tsetse-infested areas, respectively.

Two scenarios were considered with respect to potential increases of cattle sales as a result of the sustainable removal of the G. p. gambiensis population from the Niayes, i.e. a conservative scenario with a $2 \%$ annual replacement rate of the traditional system with improved ones, which was the rate observed just after tsetse eradication in Zanzibar (Vreysen et al. 2014), and a scenario with an increased replacement rate of $10 \%$ five years after the removal of the tsetse fly population. The final increase of cattle sales was estimated at $\_2800 / \mathrm{km}^{2} /$ year as compared with the total cost of the eradication campaign of $\_6400 / \mathrm{km}^{2}$. The benefit-cost analysis indicated that the project was highly cost-effective, with internal rates of return of $9.8 \%$ and $19.1 \%$ and payback periods of 18 and 13 years for the two scenarios, respectively. In addition to an increase in farmer's income, the benefits of the eradication project included a reduction of grazing pressure on the already fragile ecosystem (Bouyer et al. 2014) (Fig. 3).

The project was considered an ecologically sound approach to achieving intensified cattle production without having a significant negative impact on the environment. Although the strategy included an initial insecticide (deltamethrin) component to suppress the tsetse fly population, the insecticide use was limited to impregnation of cloth traps, targets (Laveissière et al. 1985) and nets (around pig 
pens), and direct application to cattle (Bauer et al. 1995). The Sterile Insect Technique (SIT) (Knipling 1955) used as the final eradication component in the operational phase is a non-polluting control tactic that is very environment-friendly.

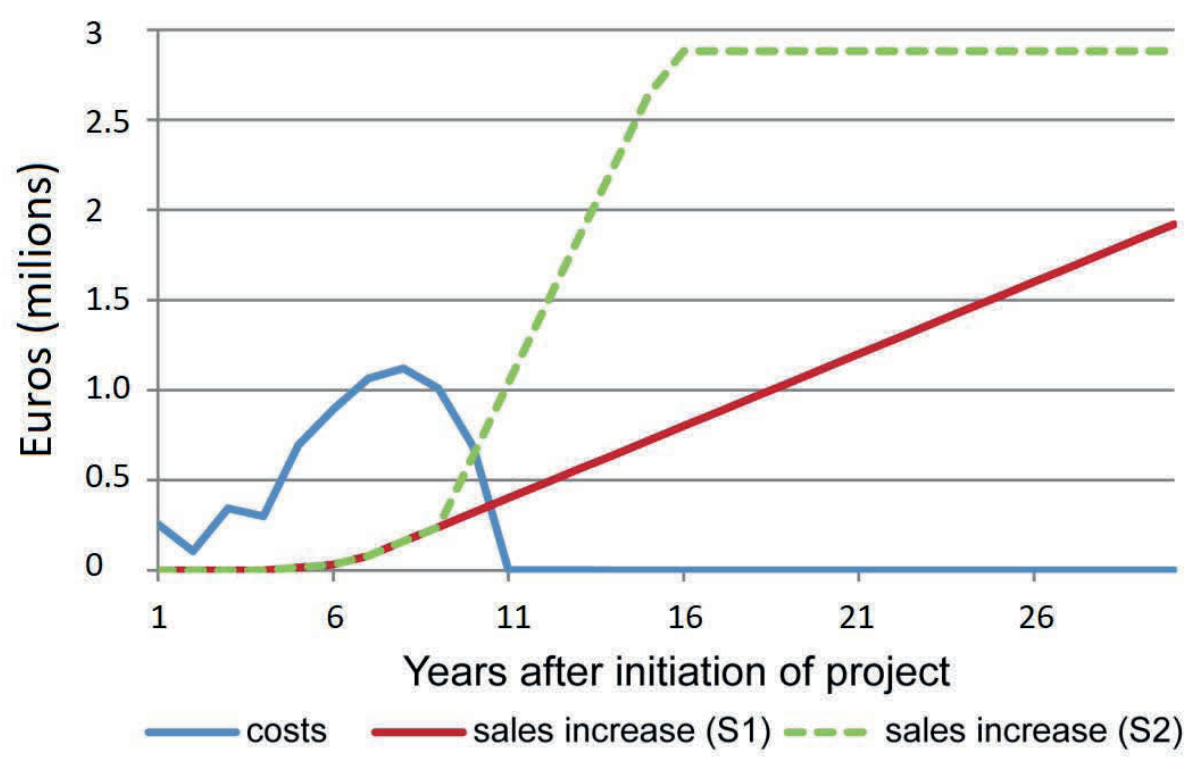

Figure 3. Comparison of the total costs of the eradication project and increase in global cattle sales per year (year $1=2007$ ) taking into account two scenarios: a $\%$ annual replacement rate (S1) of local cattle with improved breeds, and an increased replacement rate of 10\% five years after tsetse eradication (S2) (from Bouyer et al. 2014).

The SIT requires the production of large numbers of the target insect in massrearing centres, the sterilisation of the male insects using ionizing radiation (gamma rays or X-rays) and the sustained and sequential dispersal of the sterile insects over the target area in numbers large enough to outcompete the wild males for mating with wild females (Vreysen et al. 2013). The transfer of sterile sperm to wild virgin females results in embryonic arrest and hence the absence of offspring (Dyck et al. 2021). With each generation, the ratio of sterile to wild males will increase and as a result, the SIT becomes more efficient as population densities decline (inverse density dependent action of the SIT) (Vreysen and Robinson 2011).

In order to assess the potential impact of the eradication project and of the control tactics on the non-target fauna, an environmental monitoring project was implemented in five sites, one outside the tsetse-infested area (Mbour-centre IRD, a private protected area) and four within the targeted tsetse-infested areas (Dakar-Hann, Kayar, Thiès and Pout). Two fruit-feeding insect families (Coleoptera: Scarabaeidae (Cetoniinae) and Lepidoptera: Nymphalidae) were selected as indicator species as they have been shown to be highly appropriate for measuring the impact of various management practices on general ecosystem health in similar savannah areas in West Africa (Bouyer et al. 2007). 
Monitoring with banana-baited traps indicated that of the ten most abundant Cetoniinae species, only one (Pachnoda interrupta Olivier) showed a significant reduction in apparent density in Block 1 (Kayar) during the operational phase (when insecticide-impregnated traps were deployed and cattle were treated with "pour-on"), but the population recovered to pre-suppression levels one year later. Similar observations were made with another Cetoniinae species, Pachnoda marginata spp. (predominantly Pachnoda marginata aurantia (Herbst) in Block 2. No significant impact was observed with the four most abundant Nymphalidae species (Charaxes butterflies). These data indicate that the overall impact of the project, as assessed using these sensitive non-target indicator species, was transient and very limited (Bouyer, unpublished data).

In addition to the above-mentioned studies, data were collected on population dynamics of the wild G. p. gambiensis populations in four different ecological sites. Apparent densities were shown to fluctuate both in space and time. Natural abortion rates were also highly variable in space and time and were modelled using MODIS satellite data, allowing the correction of apparent abortion rates during the sterile male releases (Bouyer, unpublished data). This in turn allowed the Fried competitiveness index to be estimated (Fried 1971), considering the observed abortion rate under a given sterile to wild ratio during the pre-operational phase. These data were crucial to make correct interpretations of the monitoring data during the control operations.

In conclusion, the data that emanated from these studies contributed to the strategic decision-making and the development of a control strategy. It prompted the Government of Senegal to adopt once more an eradication strategy (Hendrichs et al. 2021), as the isolated character of the G. p. gambiensis population of the Niayes and the integration of the SIT in this third attempt offered an opportunity to create a sustainable zone free of tsetse flies and trypanosomosis. In addition, it was decided to implement a project following area-wide integrated pest management (AW-IPM) principles that aimed to integrate the various control tactics (Vreysen et al. 2007) against the entire tsetse population within the circumscribed area to ensure that no population remnants would be left after the campaign.

Moreover, there were several aspects that made the inclusion of the SIT as a component of the AW-IPM strategy a prerequisite, these were: the fragmented nature of the preferred tsetse habitat, the two earlier failures to eradicate the target population in the 1970s and 1980s (Touré 1973) and the low impact/efficiency of insecticidebased bait methods on low-density populations of the targeted species (Bouyer, unpublished data).

It needs to be emphasised that most AW-IPM projects, especially those that incorporate a SIT component, are management-intensive and technically complex. In addition to a complete set of relevant baseline data, AW-IPM projects need to be implemented following sound scientific principles (Vreysen et al. 2007), and embarking on such a project without sound baseline data and a resulting comprehensive control strategy will have a high probability of failure. The probability of success will increase significantly when the project is accompanied by an allinclusive operational research component to solve emerging problems during its implementation. 


\subsection{Phase 3: Pre-operational Phase (2009-2011)}

\subsubsection{Successful Suppression Trial in a Suitable Area of Kayar}

A pre-release suppression trial, using insecticide-impregnated Vavoua traps, was carried out in the most northern part of the target area (Kayar) between November 2009 and December 2010, to assess the efficiency of this suppression tactic. Geographic information systems (GIS) and remote sensing were used to select favourable habitat sites at which to deploy the traps at a density of 40 traps per $\mathrm{km}^{2}$ of suitable habitat, corresponding to 3.2 traps per $\mathrm{km}^{2}$ in the test area ( $8 \%$ of suitable habitat) (Bouyer, unpublished data). Monitoring data indicated that the G. $p$. gambiensis fly populations were reduced to very low numbers, which confirmed the suitability of the suppression tactic selected for this ecological zone.

\subsubsection{Establishment of an Insectary/Dispersal Centre at Dakar}

In preparation for the development of colonies (see next Section), a building at the ISRA was refurbished and modified into an insectary/dispersal centre. Essential rearing and release equipment was provided through the IAEA's Department of Technical Cooperation to enable the rearing and maintenance of the tsetse flies.

\subsubsection{G. p. gambiensis Strains and Colony Establishment}

Since the 1970s, a colony of the target species, G. p. gambiensis, has been maintained at the CIRDES, Burkina Faso (denoted BKF strain), and was used for the successful eradication of a target population from $1500 \mathrm{~km}^{2}$ of agro-pastoral land in Sidéradougou (Cuisance et al. 1984; Politzar and Cuisance 1984). From the onset of the project in Senegal, the Government decided not to develop its own mass-rearing facility to produce and sterilize the insects required for the SIT component, as the project area was judged too small to justify the expense of constructing and operating a tsetse mass-rearing facility.

Instead, it was proposed to procure the sterile male flies from the CIRDES. Although a recent study indicated that sterile males from this BKF strain were still competitive in riparian forests in Burkina Faso (Sow et al. 2012), relatively poor survival rates were obtained when released in the Parc de Hann of Dakar (B. Sall and M. Seck, unpublished data). It was speculated that this poor performance could be related to the extreme environmental conditions of this special micro-habitat in an urban setting.

To mitigate the risk that sterile males from the BKF strain would not perform in certain ecosystems in the Niayes, a decision was taken early on in the project to establish a G. p. gambiensis colony with pupae originating from Senegal (denoted SEN strain). Between October 2009 and September 2010, a total of 2185 pupae produced by wild-collected females were received at the FAO/IAEA Insect Pest Control Laboratory (IPCL), Seibersdorf, Austria, to develop a SEN colony. By the end of December 2010, the SEN colony had increased to about 450 producing female flies, and by mid-2012 the colony reached a maximum size of 4500 females. Thereafter the colony was maintained with around 1500 females (M. Vreysen, unpublished data). 
In addition, a colony was established at the IPCL with pupae derived from the BKF colony in CIRDES to develop a back-up colony for the eradication project and to provide material for experimental work, such as mating compatibility studies between the target strain (SEN) and the strain used for release (BKF), development of transport protocols of the sterile male pupae under low temperatures and the development of an introgressed strain (BKF-SEN).

In view of the fact that colonization of a wild tsetse strain is a labour-intensive and lengthy process, an introgressed strain with a genetic background of $99 \%$ from SEN, that would also retain the adaptation to an artificial rearing environment (BKF strain) was developed. However, the strain proved to have a very low fecundity and the idea was abandoned.

\subsubsection{Mating Compatibility and Competitiveness of the BKF and the SEN Strains}

In view of the marked differences between the ecosystems of Burkina Faso and Senegal, and the large genetic differences between the two populations (BKF and SEN) (Solano et al. 2010), it was important to assess under semi-natural conditions the presence or absence of any potential mating barriers between the BKF and SEN strains that could jeopardize the release component and hence the outcome of the eradication campaign.

The mating performance of the BKF strain was compared with that of the 'wildish' SEN strain (that was a few generations from the wild) in walk-in field cages. The laboratory-adapted BKF strain showed close to equal competitiveness and mating compatibility with the SEN strain, which indicated the potential of using BKF strain males for the SIT component against the G. p. gambiensis populations in the Niayes (Mutika et al. 2013). These data were later confirmed during pilot trials in the target area (Bouyer, unpublished data).

\subsubsection{Development of Protocols to Irradiate and Transport Male Tsetse Pupae}

After the decision to procure the sterile males from the CIRDES, the Government of Senegal requested the IPCL to develop irradiation and transport protocols that would allow the shipment of (only) male G. p. gambiensis pupae over long distances, whilst retaining the female flies in the colony at the CIRDES. As female tsetse flies emerge two days before male flies, a scheme was proposed that would expose the male pupae to low temperatures after most of the female flies had emerged. The low temperatures would arrest male emergence from the pupae, making transport of irradiated male pupae to Senegal possible, whilst maintaining the required low temperature.

In the first series of experiments, exposing male pupae of G. p. gambiensis to low temperatures $\left(10\right.$ and $\left.12.5^{\circ} \mathrm{C}\right)$ for 3,5 , or 7 days immediately prior to emergence had no effect on emergence of male flies, whereas emergence of flies held at $15^{\circ} \mathrm{C}$ started before the simulated transport period was over. Survival of the experimental males and fecundity of females inseminated by males that emerged from pupae held at low temperature for different periods varied within the experimental groups, but mating performance of the experimental males was not impaired (Mutika et al. 2014). 
A second series of experiments assessed the combined effect of irradiation and low-temperature period. Emergence and survival of adult male flies which were irradiated as pupae with 70, 90, 110 and 130 Gy on days 25, 27, and 29 postlarviposition was similar to that of un-irradiated pupae. Males that were irradiated with 110 Gy $24 \mathrm{~h}$ after initial exposure to the low temperatures and chilled for 5 days at $10^{\circ} \mathrm{C}$ were as competitive as un-irradiated males of the same age when competing with them in walk-in field cages for virgin untreated females (Mutika et al., unpublished data).

In addition to pupal irradiation and low temperature during their transport, the release protocol required a chilling period for adult males to allow immobilization and collection immediately prior to the aerial release (Mubarqui et al. 2014). A significantly lower proportion of males that had been irradiated (110 Gy) and held at low temperature as pupae $\left(10^{\circ} \mathrm{C}\right.$ for 5 days) and adults $\left(5.1 \pm 0.02^{\circ} \mathrm{C}\right.$ for 6 or 30 hours six days after emergence) succeeded in mating compared to untreated colony males. Female insemination levels were slightly lower for males held at low temperature for $30 \mathrm{~h}$ compared to $6 \mathrm{~h}$ or not exposed to low temperature (standard colony conditions). The data confirmed the feasibility of transporting irradiated pupae at low temperatures for long distances followed by releases of chilled males using an adult release system, but it was found necessary to minimize the time that the adults remain chilled (Mutika et al., unpublished data).

\subsubsection{Validation of Protocol for Long-distance Shipment of Irradiated Male Pupae}

The use of isothermal boxes that contained phase change material (Phase Change Material Products Limited, Cambridgeshire, UK) packs to transport the male pupae was validated during weekly shipments from 2011 to 2013. More than 900000 G. p. gambiensis pupae were transported in 132 shipments from the CIRDES in Burkina Faso, the SAS in Slovakia, and the IPCL in Austria to the ISRA in Dakar, Senegal, using a commercial courier service. The average temperature and humidity inside the insulated transport boxes were $10.1 \pm 2.3^{\circ} \mathrm{C}$ and $81.4 \pm 14.3 \%$ relative humidity, respectively. Pupae were collected on different days at the source insectary and depending on the date of collection, they were kept for different periods at low temperatures $\left(4^{\circ} \mathrm{C}\right)$.

At the emergence and dispersal centre in Senegal (ISRA), the emergence rate from pupae that had been chilled at $4^{\circ} \mathrm{C}$ for one day in the source insectary before transport (batch 2) was significantly higher than that of pupae that had been chilled at $4^{\circ} \mathrm{C}$ for two days in the source insectary before transport (batch 1), i.e. an average emergence rate $( \pm \mathrm{SD})$ of $76.1 \pm 13.2 \%$ and $72.2 \pm 14.3 \%$ respectively, with a small proportion emerging during transport $(0.7 \pm 1.7 \%$ and $0.9 \pm 2.9 \%$ respectively). Among the emerged flies at the dispersal centre, the percentage with deformed (not fully expanded) wings was significantly higher for flies from batch $1(12.0 \pm 6.3 \%)$ than from batch $2(10.7 \pm 7.5 \%)$. The quantity of sterile males available for release as a percentage of the total pupae shipped was $65.8 \pm 13.3 \%$ and $61.7 \pm 14.7 \%$ for batch 1 and 2 pupae, respectively. The results showed that the temperature inside the boxes, during shipment, must be controlled around $10^{\circ} \mathrm{C}$ with a maximal deviation of $3^{\circ} \mathrm{C}$ to maximize the male yield (Pagabeleguem et al. 2015). 


\subsubsection{Quality Control Procedures to Assess Sterile Male Quality after Long-distance Shipment}

Routine quality control procedures were required to regularly monitor the biological quality of the shipped and received biological material. This was important to ensure that the flies that were released, especially those released by air, were adequately competitive. A quality control test derived from the one used in fruit flies in Central America (Enkerlin et al. 2015) was developed to monitor the quality of G. $p$. gambiensis males that emerged from pupae produced and irradiated in Burkina Faso (irradiation done at CIRDES) and Slovakia (irradiation done at the IPCL) and transported weekly under low temperature conditions to Dakar.

For each consignment, a subsample of 50 pupae was taken before shipment and at destination to assess emergence, flight ability of the adult flies from a cylinder and survival of the flyers without access to blood meals. The quality protocol proved a good proxy of fly quality, explaining a large part of the variances of emergence rates, percentage of flies with deformed wings and flight ability in the field. Initially only $35.8 \pm 18.4 \%$ of the transported pupae produced sterile males that showed a propensity to fly, thereafter named "operational flies" (Seck et al. 2015). However, these operational males were very competitive after release, which has already resulted in eradication of some of the target populations (Bouyer et al. 2012). Over time, the handling procedures and transport protocols were fine-tuned, resulting in a significant improvement in the percentage of operational flies from an initial 36\% (SD 18\%) in 2012 to 59\% (SD 15\%) in 2016 (Fig. 4). Unfortunately, this percentage dropped again in 2017 and 2018, mainly due to problems with environmental control and bloodfeeding in the mass-rearing facilities producing the flies. Improving the quality of the flies will be crucial to ensure the success of the operational phase, as a significant positive correlation was observed between the recapture rate of sterile males in the field and this quality indicator (Bouyer and Seck, unpublished data).

\subsubsection{Environmental Suitability of Available Strains for Release in the Niayes}

At the CIRAD in Montpellier, a study was carried out to determine the critical environmental thresholds for survival of G. p. gambiensis flies from the three strains (BKF, SEN and the introgressed SEN-BKF strain). The study provided information on which strain would be best adapted to a particular environment or ecosystem. The optimal temperatures for maintaining flies of the BKF, SEN-BKF and SEN strains were $25 \pm 1,24.6 \pm 1$ and $23.9 \pm 1{ }^{\circ} \mathrm{C}$, respectively. The survival of this tsetse species was governed by temperature alone and unaffected by changing humidity within the tested range. The BKF strain better survived temperatures above these optima than the SEN and SEN-BKF strains, but a temperature of about $32^{\circ} \mathrm{C}$ was the limit for survival for all strains. The relative humidity ranging from 40 to $75 \%$ had no effect on productivity at $25-26^{\circ} \mathrm{C}$ (Pagabeleguem et al. 2016b).

\subsubsection{Field Competitiveness of the BKF Strain after Release in the Niayes}

The competitiveness, mortality and dispersal of BKF flies was measured in the field in 2010-2011 (Bouyer et al. 2012) using mark-release-recapture studies in four different ecosystems (Hann, Diaksao Peuhl, Pout and Kayar). Data were collected on 
recapture rate, trap efficiency, daily mortality of the sterile males, dispersal capacity and mating competitiveness in both space and time. Female abortion rates (i.e. rate of induced sterility) were assessed through dissection of all captured wild females (Van der Vloedt and Barnor 1984; Vreysen et al. 1996) and corrected for natural abortion rates using developed models.

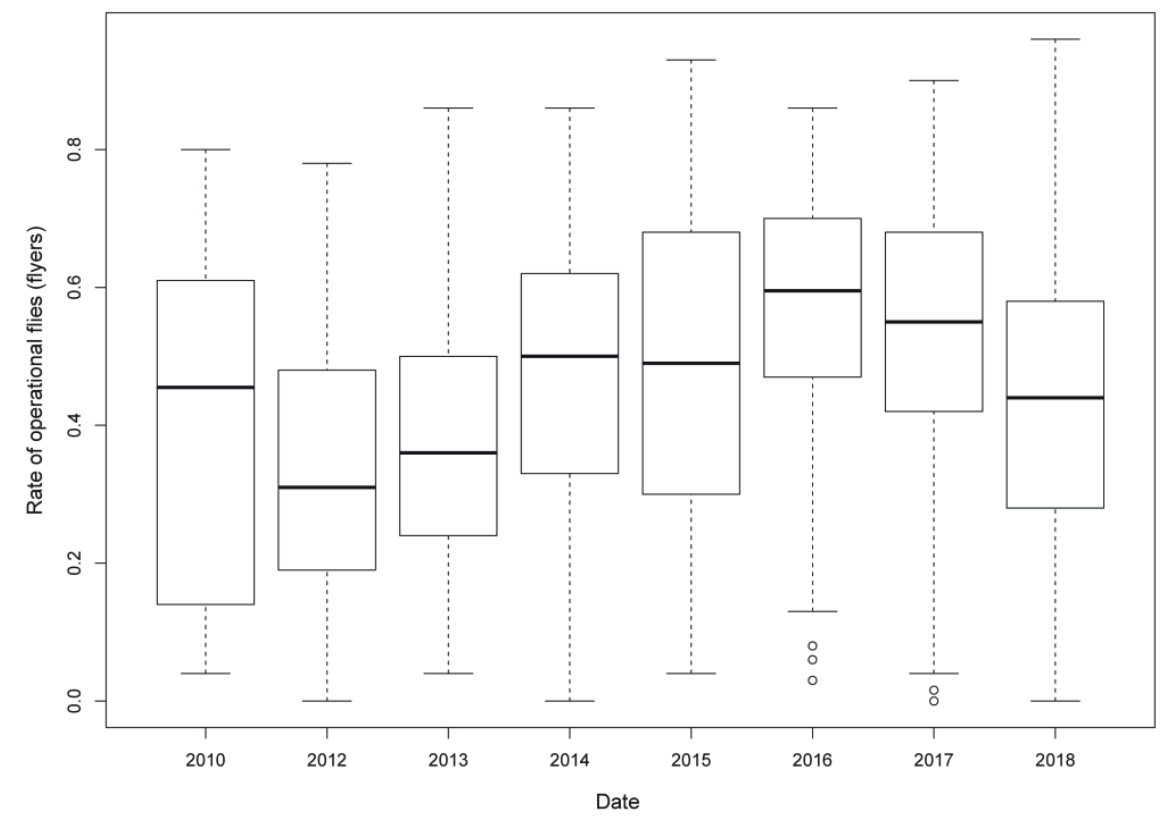

Figure 4. Rate of operational flies measured as the proportion of flies capable of flying out of a flight cylinder as part of routine quality tests at the ISRA (Institut Sénégalais de Recherches Agricoles) dispersal center (2012-2018). Boxplots present the median and quartiles and bars the 95\% confidence intervals (updated from data published in Seck et al. 2015).

Trap efficiency (measured as the probability that a trap catches a fly present within $1 \mathrm{~km}^{2}$ within 1 day (Barclay and Hargrove 2005)) was estimated at 0.03 (SD 0.04) and its variability in space and time was low. The daily mortality rate was quite homogeneous, but higher in the urban ecosystem (Parc de Hann) as compared with the more natural habitats. Although the dispersal rates were lower as compared with values obtained in riparian forests in Burkina Faso (Cuisance et al. 1984; Bouyer et al. 2007) they were, nonetheless, considered sufficient to obtain a homogeneous dispersal of sterile males using swaths of $500 \mathrm{~m}$ between aerial release lines. Finally, Fried indices obtained (Fried 1971) were high $(>0.35)$ but varied with the ecosystem. These data were instrumental in the development of an efficient release strategy for the sterile males. 


\subsubsection{Molecular Tools to Discriminate Sterile and Wild G. p. gambiensis Flies}

In any AW-IPM project with a SIT component, the impact of the released sterile males needs to be assessed at regular intervals to monitor project progress and allow quick mitigation of emerging problems. Monitoring usually relies on an adult trapping system that captures both sterile and wild insects in a similar way (Vreysen 2021). This requires procedures that allow discriminating between the trapped wild and sterile male insects.

In the tsetse eradication project in Senegal, sterile adult male G. p. gambiensis were marked with a fluorescent dye powder (DayGlo ${ }^{\circledR}, 1 \%$ dye by weight mixed with sand) during emergence from the pupae (Parker 2005). A similar procedure was used in the Glossina austeni Newstead eradication project on Unguja Island of Zanzibar (Vreysen 1995). This type of marking is effective, although not infallible and in some cases, sterile male flies were only slightly marked; conversely, some wild flies could become contaminated with a few dye particles in the cages of the monitoring traps (which leads to incorrect interpretation of the trapping results).

In some cases, predatory ants also damaged the trapped flies, making discrimination between wild and sterile males using a fluorescence camera and / or a fluorescence microscope difficult.

A molecular technique, based on the determination of cytochrome oxidase haplotypes of G. p. gambiensis, was therefore developed to discriminate wild from sterile males with a high level of accuracy. DNA was isolated from the fly heads and a portion of the 5' end of the mitochondrial gene cytochrome oxidase I was amplified for sequencing. All sterile males from the BKF strain displayed the same haplotype and differed from that of wild male flies trapped in Senegal (and in Burkina Faso). The method allowed complete and fail-proof discrimination between sterile and wild male G. p. gambiensis and might be used in other tsetse control campaigns with a SIT component (Pagabeleguem et al. 2016a).

\subsubsection{Aerial Release Trials}

Sterile male tsetse flies were released by air for the first time in the G. austeni eradication campaign on the Island of Unguja, Zanzibar (Vreysen et al. 2000), using biodegradable carton boxes that contained un-chilled sterile adult insects. The fixedwing aircraft were equipped with an appropriate chute that allowed the cartons to be released through the fuselage of the aircraft (Vreysen et al. 2000).

In the Niayes project, the area that needed to be covered with sterile males was large enough to opt for aerial releases to efficiently disperse the sterile insects, rather than ground releases which were considered too costly, inefficient and not conducive to an area-wide coverage. The release vehicle of choice was the gyrocopter (Fig. 5), which was initially adapted to release sterile males in carton release containers. A gyrocopter is an autogyro that is characterized by a free-spinning rotor that turns because of the passage of air through the rotor from below which sustains the autogyro in the air, and a separate engine driven propeller that provides forward thrust (Wikipedia 2019). 


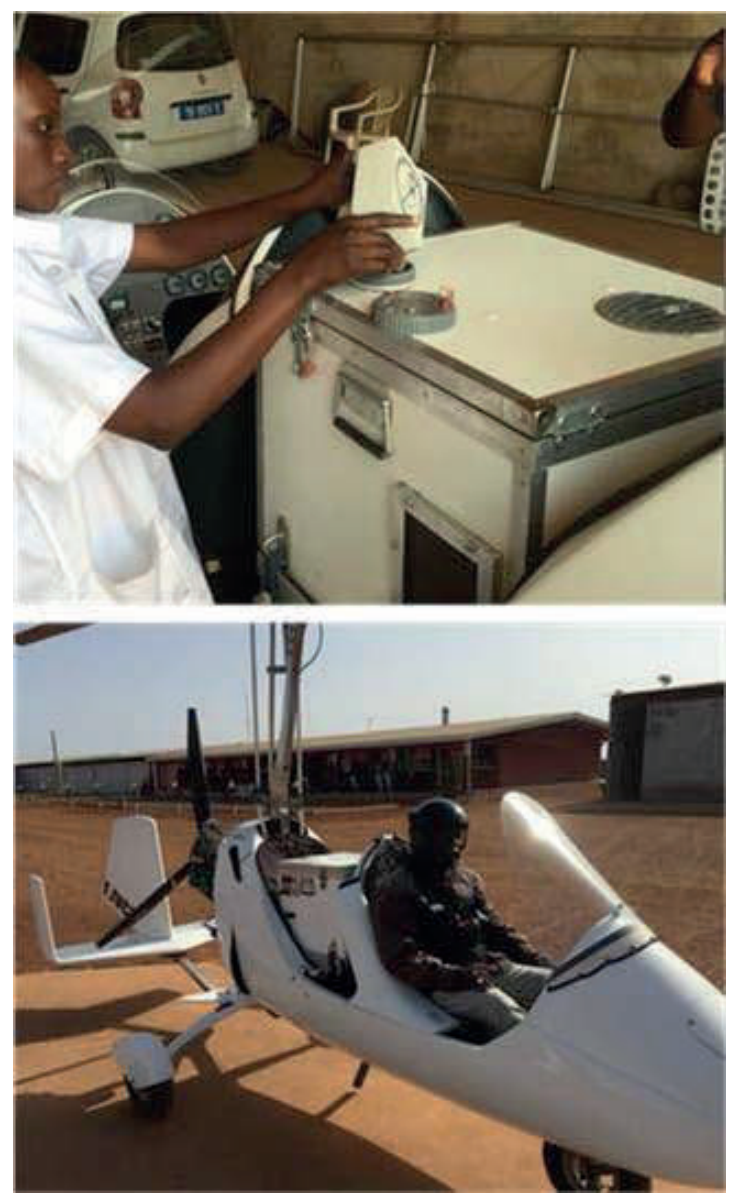

Figure 5. Loading of the chilled adult aerial release device with immobilized adult tsetse males (top) and the gyrocopter ready for take-off to release the sterile insects (bottom).

Gyrocopters have been used for the SIT component in other AW-IPM projects, such as the release of sterile false codling moth, Thaumatotibia leucotreta Meyrick, in South Africa (Boersma, this volume).

The aerial release of sterile males using carton boxes was tested in a sub-unit of the first block (Kayar) along 4 release lines that were separated with a swath of 500 m. For 11 weeks (from March 2013 to June 2013), 32 boxes were released each week separated by a distance of $500 \mathrm{~m}$ over each release line. A total of 65000 sterile males were released of which 316 flies $(0.5 \%)$ were recaptured, giving an estimated daily mortality rate of $28 \%$ (SD 12\%) and a mean daily displacement of $917 \mathrm{~m}$ (SD $477 \mathrm{~m}$ ).

Although the release with carton boxes was very successful, a new approach for the aerial release of sterile tsetse flies was developed in collaboration with the Mubarqui group of Mexico (Mubarqui et al. 2014). This innovative system (Fig. 5) allowed the release of small numbers of tsetse flies per surface area (between 10-100 
per $\mathrm{km}^{2}$ ) and was based on the use of a vibrating mechanism. The device is guided by a GIS that can adjust flexibly the density of sterile males to be released depending on the requirements of the different target areas being treated. The GIS is installed on an android tablet which enables the pilot to concentrate on navigating the predefined release lines; the machine will automatically start releasing the required number of sterile insects for each target zone. However, the calibration of the release rate using the release machine proved challenging because of significant (unwanted) secondary vibrations of the gyrocopter. As a consequence, a new release device was designed, based on a rotating cylinder, which provided improved results (patent deposition number 1653994 by CIRAD and ISRA).

\subsubsection{Use of a Maxent Distribution Model}

All suppression and release activities were optimized using a Maxent distribution model that mixed high spatial resolution data (four supervised classifications of the vegetation Landsat 7ETM+ images from four seasons) with high temporal resolution data (MODIS images) that allowed a very good identification of suitable habitats (Dicko et al. 2014). The model was used to select and deploy insecticide-impregnated traps in suitable vegetation (see above), but also to adjust the release density of the sterile males in relation to the availability of suitable habitat (the reference was 10 and 100 sterile males per $\mathrm{km}^{2}$ in unsuitable and suitable habitat, respectively).

\subsection{Phase 4: Operational Phase (since 2011)}

\subsubsection{External Review of the Project}

An external team of experts visited the project in May 2012 and reviewed all past activities since the initiation of the project. The evaluation team highlighted the thoroughness of the baseline data collection effort that enabled the project area to be defined. The reviewers likewise emphasized the good collaboration, complementarities and interaction between the persons involved in the project as a key factor for the project's success. The team concluded that the project was ready to enter the full operational eradication phase (unpublished report to the IAEA of an external review team-May 2012).

\subsubsection{The "Rolling Carpet" Strategy}

Although the G.p. gambiensis populations in the target area were genetically isolated from the remainder of the tsetse belt in the south-eastern part of Senegal, the lack of sufficient manpower in the field and insufficient numbers of sterile males available on a weekly basis made it impossible to tackle the entire project area at once.

During the baseline data collection, it became apparent that the project area contained three distinct tsetse populations in areas of suitable habitat that were separated from each other by zones of unsuitable habitat (or very fragmented suitable habitat), limiting the potential for tsetse dispersal. The project area was therefore divided into three main operational blocks, i.e. Kayar in the north (Block 1), Pout/Sebikotane/Diacksao Peulh in the middle (Block 2) and Dakar (Block 3B) and Thiès (Block 3B), west and east of Block 2, respectively (Fig. 6). 


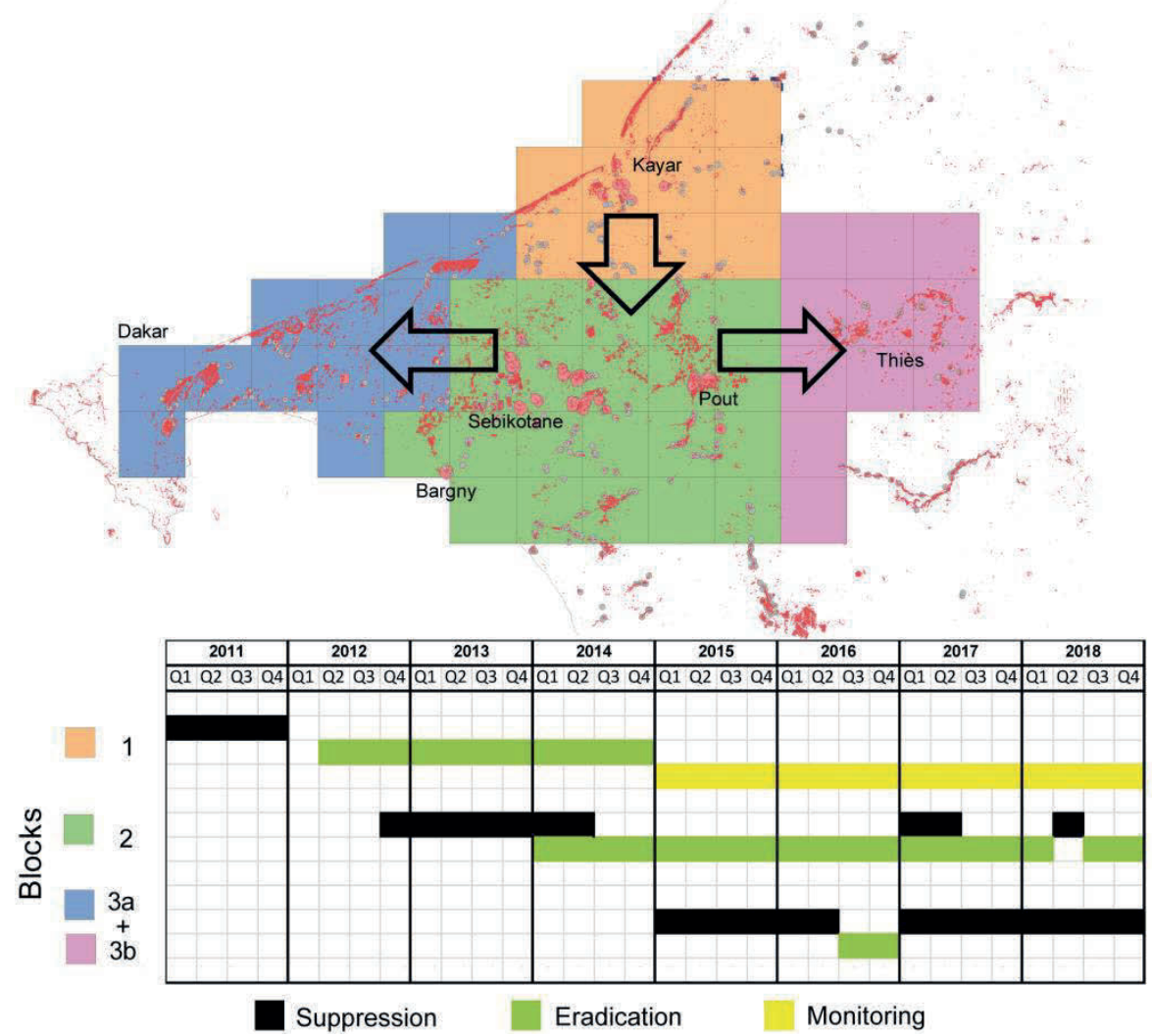

Figure 6. Map of project area with each grid cell corresponding to $5 \times 5 \mathrm{~km}$. Diagram of the three main activities of the operational phase in the different blocks of the project area.

An operational "rolling carpet" strategy (Hendrichs et al. 2021) was adopted and implemented whereby the different blocks were treated in sequence (suppression, followed by sterile male releases, and then monitoring of the status of eradication) (Fig. 6). In each block, insecticide-impregnated targets/traps were removed before the start of sterile male releases.

In Block 1, January 2011 marked the start of the operational phase of the project with the deployment of 269 insecticide-impregnated Vavoua traps (Laveissière and Grébaut 1990) in the favourable habitat areas, a density which corresponded to 19.4 traps per $\mathrm{km}^{2}$ of suitable habitat. The apparent density of the G. p. gambiensis population dropped from an average of 0.42 (SD 0.39) flies per trap per day before the start of the suppression to an average of 0.04 (SD 0.11) flies per trap per day at the end of the trap deployment. This was followed by the aerial release of sterile males in March 2012 using biodegradable cardboard boxes over 185 release points, following 23 release lines over a total surface area of $72 \mathrm{~km}^{2}$. In February 2014, the "boxed release" system was abandoned, and a "chilled adult" release system became operational (Mubarqui et al. 2014). 
The apparent density of the G. p. gambiensis fly population was reduced to zero catches after six months of sterile male releases. In Block 1, the last wild fly was trapped on August 9, 2012, i.e. an old female (> 40 days), which was in her fourth oviposition cycle and which had an empty uterus. The next follicle in ovulation sequence was still immature and small, indicating an abortion of the larvae or an egg in embryonic arrest. This female showed a copulation scar and a spermathecal fill of $85 \%$, indicating that its sterility was probably induced through a mating with a sterile male (Van der Vloedt and Barnor 1984; Vreysen et al. 1996).

From the beginning of the releases in Block 1 (March 16, 2012) to the date corresponding to the last capture, only three other wild females could be dissected, and all had indications of having mated with a sterile male. The average percentage of sterile males as a proportion of the total catch was then $99.2 \%$ (SD 1.6\%), corresponding to a sterile-to-wild male ratio of 130:1. The percentage of sterile males remained $100 \%$ thereafter (no wild fly has been captured for the subsequent 78 weekly collections with 25 monitoring traps). Sterile male releases were suspended in late 2014 and as of January 2015, all sterile flies were released in Block 2.

The monitoring in Block 1 was continued on a monthly basis and is still ongoing at the time of writing. Since 2012, no wild flies have been trapped in Block 1, corresponding to a very high likelihood of eradication (probability of not detecting potential remaining flies $<10^{-6}$ at the time of writing, considering that the population would have recovered to at least 10 flies during almost 2 years of monitoring without control) (Fig. 7, upper graph).

In Block 2, remote sensing and land cover maps were used to select 1205 suitable habitat sites for the deployment of insecticide-impregnated traps (corresponding to 16.7 traps per $\mathrm{km}^{2}$ of suitable habitat and 2.7 traps per $\mathrm{km}^{2}$ of the total targeted area). Deployment of the suppression traps in Block 2 was initiated in December 2012 and was supplemented with an additional 300 insecticide-impregnated traps in early 2013. In addition, at 6 monthly intervals, 2970 cattle were treated three times with a "pouron" insecticide as a complementary method to suppress the G. p. gambiensis fly population.

In Block 2, the apparent fly density dropped from an average of 1.24 (SD 1.23) flies per trap per day before the suppression to an average of 0.005 (SD 0.017) flies per trap per day at the end of the suppression phase. Sterile male releases were started in Block 2 in February 2014, initially covering a quarter of the block, which was expanded based on sterile male availability to half of the block in April 2014. In January 2015, releases were expanded to cover the entire Block 2.

The apparent fly density was reduced to $<0.001$ fly per trap per day by the end of 2018. The releases are scheduled to continue for another 10-12 months after the last wild fly has been trapped (Fig. 7, middle graph). In the beginning of 2017 and 2018 unexpected upsurges in the density of the wild fly population were observed in Block 2 in 3-5 areas. The reasons for these upsurges are not clear, but mitigating action was taken immediately, and suppression traps were deployed in the affected areas (Fig. 6). In addition, emergency insecticide spraying of Euphorbia hedges was carried out in selected areas, that brought the fly situation rapidly again under control. Depending on availability of sterile male flies, these areas received higher concentrations of sterile flies as compared to the rest of the area. 
Ground releases were carried out in an area of $114 \mathrm{~km}^{2}$ in Block 2, where recapture rates of sterile males released by air were consistently zero. This was later assumed to be correlated with the opening of a cement factory that apparently had a negative impact of fly survival. As a result, the aerial releases in that area were abandoned and replaced with releases from the ground. Additional ground releases were used in the hot spot areas of Block 2 (Pout and Diacksao Peulh) to supplement the aerial releases.

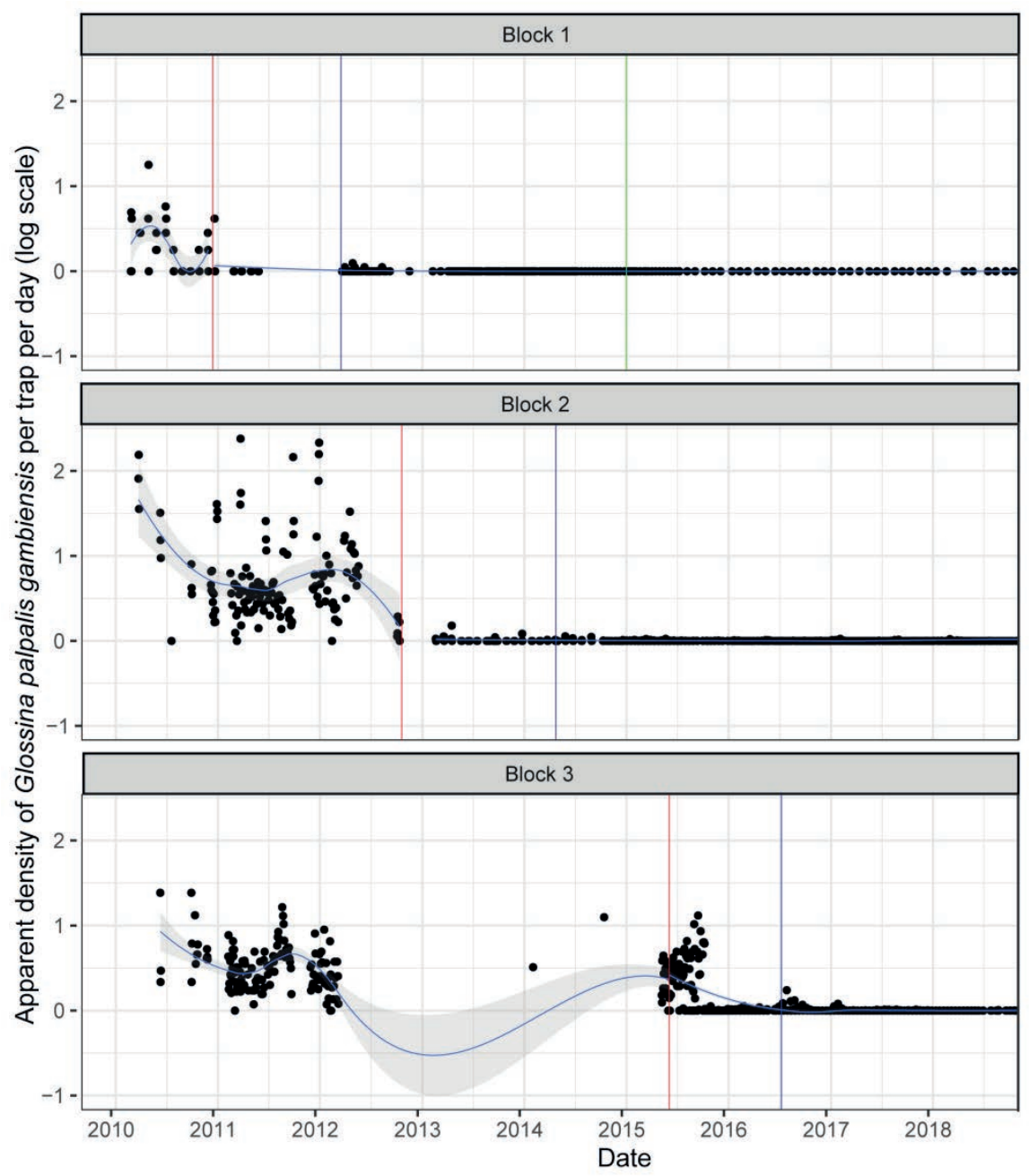

Figure 7. Apparent density (number of flies/trap/day) of the Glossina palpalis gambiensis populations in Block 1, 2 and 3 of the Niayes during the pre-suppression, suppression and eradication activities. Pre-suppression activities are shown before the blue line, suppression between the blue and red lines, eradication activities with sterile male releases between the red and green lines, and post-SIT monitoring only after the green line. 
In Block 3, the suppression activities started in May 2015 with the deployment of 191 insecticide-impregnated traps in suitable habitat (12.6 traps per $\mathrm{km}^{2}$ of suitable habitat), thereafter reinforced with an additional 43 traps. Before suppression, the initial apparent density of the fly population was 1.50 (SD 2.12) flies per trap per day; this dropped to 0.008 (SD 0.039) flies per trap per day in June 2016, i.e. a reduction of $99.4 \%$. Sterile male releases were started in July 2016 in $100 \mathrm{~km}^{2}$ of Block 3, but were suspended in early 2017, to accommodate the releases in the problem areas in Block 2 (Fig. 7, lower graph).

\subsubsection{Monitoring the Progress of the Campaign}

The Maxent distribution model was also used to guide the monitoring of the eradication campaign by deploying monitoring traps in suitable habitats (Dicko et al. 2014). As eradication was the selected strategy, the suitability threshold was set to provide a high sensitivity $(0.96)$. The model was continuously improved during the project to increase its specificity from an initial 0.43 using the supervised classifications of the vegetation to 0.57 using the Maxent.

The areas around the monitoring traps were regularly cleared of vegetation and the monitoring traps were changed every 3 months. Moreover, monitoring traps in sites with no capture for one year were moved to other sites, but still within the predicted suitable habitats, and were labelled as temporary monitoring sites.

Regular parasitological monitoring of sentinel herds, each composed of $\sim 100$ tagged cattle, was carried out every year in three sites, of which one site was in a noninfested area and two were in the target area (in Blocks 1 and 2). In the non-infested area, the overall AAT seroprevalence remained below 5\% between 2009 and 2017. In the target area, the AAT prevalence reduced quickly as control operations advanced $(\mathrm{p}<0.001)$, i.e. from an initial value of $>20 \%$ in 2009 to below $1 \%$ in 2014 in Block 1, and from 60-85\% in 2009-2010 to below 5\% in 2016 and 2017 in Block 2 (Bouyer and Seck, unpublished data).

In 2015, irregular sero-prevalence peaks of $T$. vivax were observed in both blocks, i.e. $12 \%$ in Block 1 and $16 \%$ in Block 2, which might be attributed to mechanical transmission (Desquesnes and Dia 2003; Desquesnes et al. 2009) facilitated by the presence of trypanosomes in tsetse in Block 3 and a small persistence in Block 2.

A blanket treatment of all cattle using trypanocidal drugs will be carried out in the Niayes area after tsetse eradication, to also ensure the eradication of trypanosomes.

\section{DISCUSSION AND PERSPECTIVES}

Many successful AW-IPM projects with a SIT component were or are implemented by management structures that were/are flexible and independent, with a high degree of financial and political freedom and not affected by strangling government bureaucracies and regulations (Vreysen et al. 2007). The New World Screwworm Commission, initially established between Mexico and the USA and later other countries in Central America, is a good example in this respect (Wyss 2006). The commission had to account for all financial, physical and human resources, could hire and fire staff based on merit and performance, and all staff were employed full-time without any other responsibilities (Vreysen et al. 2007). 
Another good example is the Programa Moscamed, a cooperative agreement between Mexico, Guatemala and the USA, that has contained the Mediterranean fruit fly, Ceratitis capitata (Wiedemann) for the last 30 years in Guatemala and has prevented its spread into Mexico and the USA, which are free from this pest (Enkerlin et al. 2015).

There are however examples of AW-IPM projects, albeit smaller than the examples given above, that operated successfully outside such an organization, e.g. the tsetse eradication project on Unguja Island of Zanzibar that was implemented within the Ministry of Agriculture, Livestock and Environment of Zanzibar (Vreysen et al. 2000). The success of the project, however, was made possible by the full autonomy and independence that was given to the senior project managers by the Government of Zanzibar to implement the project as required.

The project in the Niayes is likewise operated within the Ministries of Livestock and Agriculture (EXPO Milano 2015) and not implemented by an independent organization. The project adopted an "adaptive management" approach which included monthly project coordination meetings with the different stakeholders (Fig. 8). It is believed that this approach was critical to the project's success. This management approach involved all the stakeholders, including researchers, ensuring transparency and decision-making by consensus. The important decisions in the project were based on scientific principles (never political, personal, or emotional) and were guided by analysed field or other data. Day-to-day operational and financial problems were openly discussed, leading to consolidated solutions being found. Any decision that required follow-up actions was immediately acted upon and was always implemented according to plan, as the DSV and the ISRA had full authority over regional veterinary staff and technicians employed for the SIT component of the project, respectively. It is believed that the collaboration between the internal stakeholders, international partners and the policy of "non-interference" of the respective Ministries have been instrumental for the smooth implementation of the project.

The stability in project staffing, with basically no turn-over experienced in 12 years, both at the management and at the technical (insectary/field staff) level is considered another important factor for the project's success. This created a personnel culture of reliability, transparency and trust, and ensured the necessary institutional memory. The main outputs of the research component of this innovative project were the development of methods that allowed an optimization of the implementation of the SIT to eradicate the tsetse fly using an adaptive management scheme. The involvement of the public sector in the innovation processes guaranteed top-down control of the use of the technology from the central veterinary services to regional veterinary services or dedicated personnel (Devaux-Spatarakis et al. 2016).

All data generated within the project were transferred to and managed within a relational database that was accessible on the web with information displayed in graphs, featuring specific queries that allowed all stakeholders and the general public to make assessments of the progress of the project at any time and at a glance (Projet de Lutte contre la Mouche Tsé-tsé dans le Niayes 2019). This provided transparency on project progress for all stakeholders in the project and also facilitated statistical analyses of the field data to better inform the decision-making process. 
Before the start of the operational phase of the project and after a critical review of its components, the Senegalese Ministry of the Environment issued a permit to implement the planned project, provided that it was accompanied by an environmental monitoring scheme for the entire life span of the project. This monitoring revealed a slight and transitory impact of the suppression activities on non-target fauna (Ciss et al. 2019). The removal of the tsetse fly and AAT from the Niayes is expected to result in an improvement of farming systems (i.e. a replacement of traditional, low-productive cattle with more productive cross- and/or exotic breeds-this replacement is already apparent in Block 1 and certain areas of Block 2), but at the same time in an anticipated reduction (up to $45 \%$ ) of the average size of cattle herds (Bouyer et al. 2014, 2015a). This will actually significantly reduce overgrazing which is a major cause of land degradation in Senegal, and as such, the removal of the tsetse fly will have a positive impact on this already fragile ecosystem and environment (Budde et al. 2004). Despite the experienced upsurges of the wild fly population in the beginning of 2017-2018 period, the apparent density of the wild fly population has been significantly reduced in the entire project area and transmission of AAT has basically stopped in the Niayes at the time of writing. Consequently, milk production, resulting from an increased rate of replacement of local with exotic cattle, has significantly increased and milk import has significantly been reduced. In 2016-2017, Senegal imported more than 1000 exotic cattle into the Niayes area as compared to 100-200 in earlier years.

An important part of the operational funding was provided by international partners, such as the IAEA's Department of Technical Cooperation and the US Department of State's PUI. The socio-economic studies which were carried out documented the processes of innovation that increased the impact of the eradication project (Bouyer et al. 2014, 2015a), and the outcome of these studies were important to convince external partners to continue financing the project, even though it could take some time for the economic impact of the project to become visible.

Like many other AW-IPM projects with a SIT component, the AW-IPM campaign in the Niayes was accompanied by an extensive public relations campaign. The inhabitants of the Niayes were informed from the beginning and during the different phases of the project about the justification, activities, future advantages of the project through meetings organized by the Chiefs of the local veterinary centres in collaboration with administrative (sub-prefects) and local (village chiefs and locally elected politicians) authorities. It is believed that these meetings were instrumental in informing the general public about the project and soliciting their support. Even in the beginning of the project, the period of baseline data collection was taken as an opportunity to inform and intensify contacts with the local farming community regarding the project. In addition, T-shirts and hats were distributed that carried the logo of the project to increase the visibility of the project. Finally, two video films produced in 2012 and 2013 were aired on the national TV.

As was done for Block 1, probability models will also be used to verify eradication over the entire project area (Barclay and Hargrove 2005). These calculations might be complemented by a new innovative diagnostic technique that is based on the prevalence of specific antibodies against tsetse saliva in the host that can persist for 4-6 weeks, which is being developed as an indirect - but very sensitive - measure of tsetse presence (Somda et al. 2013, 2016). 


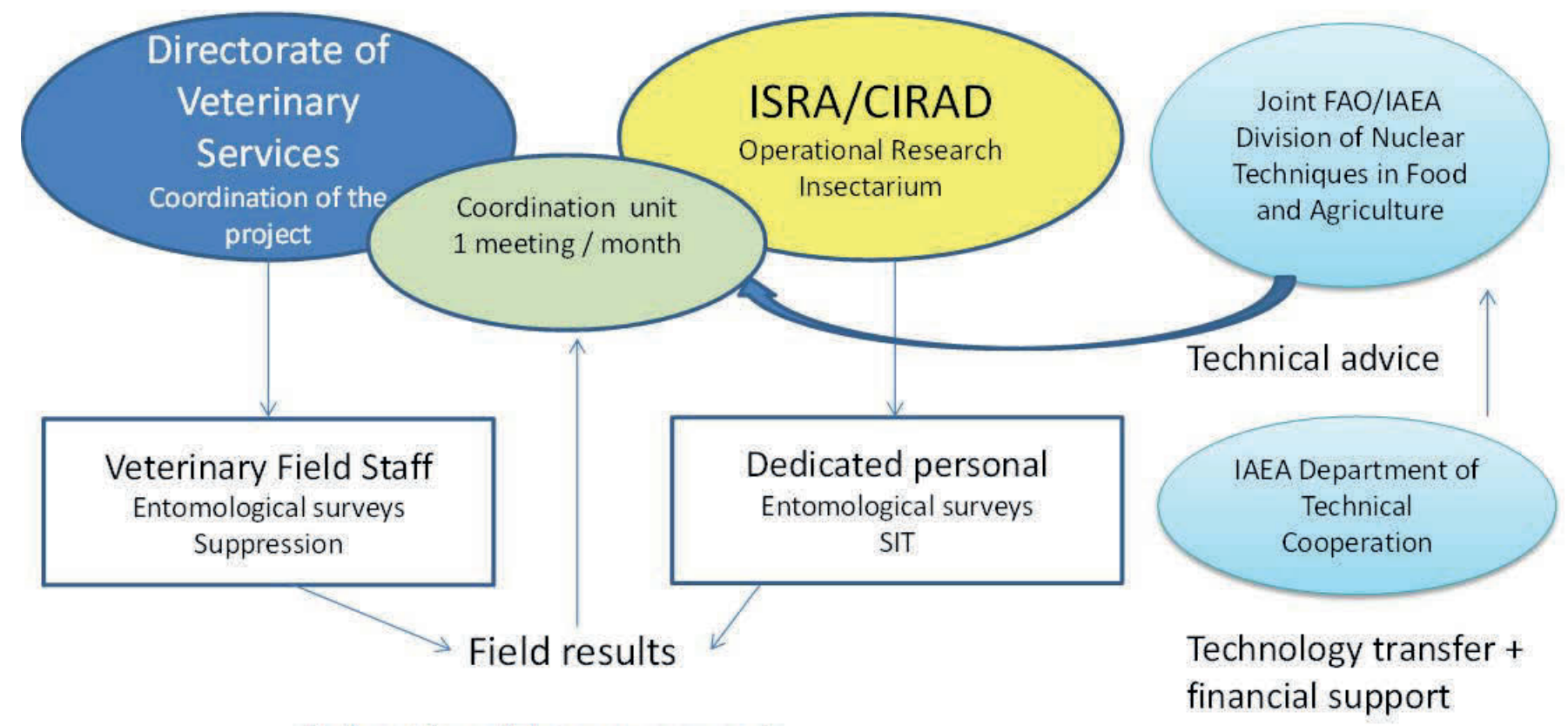

\section{Adaptive Management}

Figure 8. Organigramme of the adaptive management philosophy adopted by the project. (CIRAD = Centre de Cooperation Internationale en Recherche Agronomique pour le Développement; ISRA = Institut Sénégalais de Recherches Agricoles; IAEA: International Atomic Energy Agency; FAO: Food and Agriculture Organization of the United Nations 
The absence of circulation of the AAT parasites will also be used as an indirect measure of the absence of cyclical transmission and hence, the absence of tsetse flies. All these data will permit the provisional declaration of tsetse eradication after there have been zero fly catches for a period of six months and confirmed tsetse eradication if no wild tsetse are captured during for least one year after the end of control operations (Barclay et al. 2021).

Finally, friction models have been developed and used to identify other potential G. p. gambiensis populations that could be potential targets for eradication (Bouyer et al. 2015b). These models allow the resistance of the environment to tsetse dispersal to be mapped, i.e. natural barriers isolating sub-populations from the main tsetse belt. These "ecological islands" of suitable habitats might be good candidates for tsetse eradication projects, but feasibility studies similar to those described in the present paper will be necessary to accurately assess their boundaries and confirm their isolated status with respect to neighbouring populations. The method could be used to prioritize intervention areas elsewhere in Africa within the PATTEC initiative and is applicable to the strategic management of other vector and pest species.

\section{ACKNOWLEDGMENTS}

We would like to thank the staff of the following organizations for their technical and/or financial support during the implementation of this project: the Ministère de l'Elevage et des Productions Animales, the Ministère de l'Agriculture et de l'Equipement Rural, the Ministère de l'Environnement et du Développement Durable, the ANACIM (Agence Nationale de l'Aviation Civile et de la Météorologie, the military airstrip of Thiès, the CIRAD, the IRD, the FAO/IAEA Insect Pest Control Laboratory, the FAO, the SAS, the CIRDES, the PATTEC office in Burkina Faso, the IAEA's Department of Technical Cooperation, the Mubarqui group in Mexico, l'Ecole Senegal-Japon, and the US Department of State.

This publication is dedicated to the memory of Mr Alphonse Manga of the Ministry of Livestock and Animal Production, Senegal and Mr Idrissa Kaboré, CIRDES, Burkina Faso.

\section{REFERENCES}

Barclay, H. J., and J. W. Hargrove. 2005. Probability models to facilitate a declaration of pest-free status, with special reference to tsetse (Diptera: Glossinidae). Bulletin Entomological Research 95: 111.

Barclay, H. J., J. W. Hargrove, A. Meats, and A. Clift. 2021. Procedures for declaring pest free status, pp. 923-948. In V. A. Dyck, J. Hendrichs, and A. S. Robinson (eds.), Sterile Insect Technique Principles and practice in Area-Wide Integrated Pest Management. Second Edition. CRC Press, Boca Raton, Florida, USA.

Bauer, B., S. Amsler-Delafosse, P. Clausen, I. Kabore, and J. Petrich-Bauer. 1995. Successful application of deltamethrin pour-on to cattle in a campaign against tsetse flies (Glossina spp.) in the pastoral zone of Samorogouan, Burkina Faso. Tropical Medicine and Parasitology 46: 183-189.

Bouyer, F., M. T. Seck, A. Dicko, B. Sall, M. Lo, M. Vreysen, E. Chia, J. Bouyer, and A. Wane. 2014. Ex-ante cost-benefit analysis of tsetse eradication in the Niayes area of Senegal. PLoS Neglected Tropical Diseases 8: e3112. 
Bouyer, F., J. Bouyer, M. T. Seck, B. Sall, A. H. Dicko, R. Lancelot, and E. Chia. 2015a. Importance of vector-borne infections in different production systems: Bovine trypanosomosis and the innovation dynamics of livestock producers in Senegal. Revue Scientifique et Technique (International Office of Epizootics) 34: 199-212.

Bouyer, J., L. Guerrini, M. Desquesnes, S. de la Rocque, and D. Cuisance. 2006. Mapping African animal trypanosomosis risk from the sky. Veterinary Research 37: 633-645.

Bouyer, J., Y. Sana, Y. Samandoulgou, J. César, L. Guerrini, C. Kabore-Zoungrana, and D. Dulieu. 2007. Identification of ecological indicators for monitoring ecosystem health in the trans-boundary $\mathrm{W}$ Regional park: A pilot study. Biological Conservation 138: 73-88.

Bouyer, J., M. T. Seck, B. Sall, L. Guerrini, and M. J. B. Vreysen. 2010. Stratified entomological sampling in preparation of an Area-Wide Integrated Pest Management project: The example of Glossina palpalis gambiensis in the Niayes of Senegal. Journal of Medical Entomology 47(4): 543552.

Bouyer, J., M. T. Seck, S. Pagabeleguem, B. Sall, M. Lo, M. J. B. Vreysen, T. Balenghien, and R. Lancelot. 2012. Study of the competitiveness of allochtonous sterile males during the tsetse eradication campaign in Senegal. In European Society of Vector Ecology (ed.), 18th Conférence E-SOVE 2012. EID, CIRAD, IRD, Montpellier, France.

Bouyer, J., A. H. Dicko, G. Cecchi, S. Ravel, L. Guerrini, P. Solano, M. J. B. Vreysen, T. De Meeûs, and R. Lancelot. 2015b. Mapping landscape friction to locate isolated tsetse populations candidate for elimination. Proceedings National Academy of Sciences of the USA 112: 14575-14580.

Brunhes, J., D. Cuisance, B. Geoffroy, and J.-P. Hervy. 1998. Les glossines ou mouches tsé-tsé CIRAD/ORSTOM, Montpellier, France.

Budde, M. E., G. Tappan, J. Rowland, J. Lewis, and L. L. Tieszen. 2004. Assessing land cover performance in Senegal, West Africa using 1-km integrated NDVI and local variance analysis. Journal Arid Environments 59: 481-498.

Camara, M., H. Harling Caro-Riaño, S. Ravel, J.-P. Dujardin, J.-P. Hervouet, T. de Meeüs, M. S. Kagbadouno, J. Bouyer, and P. Solano. 2006. Genetic and morphometric evidence for isolation of a tsetse (Diptera: Glossinidae) population (Loos islands, Guinea). Journal of Medical Entomology 43: $853-860$.

Ciss, M., M. D. Bassène, M. T. Seck, B. Sall, A. G. Fall, M. J. B. Vreysen, and J. Bouyer. 2019. Environmental impact of tsetse eradication in Senegal. Scientific Reports 9:20313.

Desquesnes, M., and M. L. Dia. 2003. Trypanosoma vivax: Mechanical transmission in cattle by one of the most common African tabanids, Atylotus agrestis. Experimental Parasitology 103: 35-43.

Desquesnes, M., F. Biteau-Coroller, J. Bouyer, M. L. Dia, and L. D. Foil. 2009. Development of a mathematical model for mechanical transmission of trypanosomes and other pathogens of cattle transmitted by tabanids. International Journal of Parasitology 39: 333-346.

Devaux-Spatarakis, A., D. Barret, J. Bouyer, C. Cerdan, M.-H. Dabat, G. Faure, T. Ferré, E. Hainzelin, I. Medah, L. Temple, and B. Triomphe. 2016. How can international agricultural research better contribute to innovations' impacts: Lessons from outcomes analysis. In Social and technological transformation of farming systems: Diverging and converging pathways. 14 pp. European IFSA Symposium, July 2016, Newport, UK.

Dicko, A. H., R. Lancelot, M. T. Seck, L. Guerrini, B. Sall, M. Lo, M. J. B. Vreysen, T. Lefrançois, F. Williams, S. L. Peck, and J. Bouyer. 2014. Using species distribution models to optimize vector control: The tsetse eradication campaign in Senegal. Proceedings of the National Academy of Sciences of the USA 111: 10149-10154.

Dyck, V. A., J. Hendrichs, and A. S. Robinson (eds.). 2021. Sterile Insect Technique - Principles and practice in Area-Wide Integrated Pest Management. Second Edition. CRC Press, Boca Raton, Florida, USA. 1200 pp.

Enkerlin, W., J. M. Gutiérrez-Ruelas, A. V. Cortes, E. C. Roldan, D. Midgarden, E. Lira, J. L. Z. López, J. Hendrichs, P. Liedo, and F. J. T. Arriaga. 2015. Area freedom in Mexico from Mediterranean fruit fly (Diptera: Tephritidae): A review of over 30 years of a successful containment program using an integrated area-wide SIT Approach. Florida Entomologist 98: 665-681.

EXPO Milano 2015. Eradicating the tsetse fly to save farms in Senegal. Five questions for the Directorate of Veterinary Services. Removing the tsetse fly results in tripling milk and meat sales in Senegal.

Feldmann, H. U., S. Leak, and J. Hendrichs. 2018. Assessing the feasibility of creating tsetse and trypanosomosis-free zones. International Journal of Tropical Insect Science 38: 77-92. 
Feldmann, U., V. A. Dyck, R. C. Mattioli, J. J. Jannin, and M. J. B. Vreysen. 2021. Impact of tsetse fly eradication programmes using the Sterile Insect Technique, pp. 1051-1080. In V. A. Dyck, J. Hendrichs, and A. S. Robinson (eds.), Sterile Insect Technique - Principles and practice in Area-Wide Integrated Pest Management. Second Edition. CRC Press, Boca Raton, Florida, USA.

Fried, M. 1971. Determination of sterile-insect competitiveness. Journal of Economic Entomology 64: 869-872.

Guerrini, L., J. P. Bord, E. Ducheyne, and J. Bouyer. 2008. Fragmentation analysis for prediction of suitable habitat for vectors: The example of riverine tsetse flies in Burkina Faso. Journal of Medical Entomology 45: 1180-1186.

Hendrichs, J., M. J. B. Vreysen, W. R. Enkerlin, and J. P. Cayol. 2021. Strategic options in using sterile insects for Area-Wide Integrated Pest Management, pp. 841-884. In V. A. Dyck, J. Hendrichs, and A. S. Robinson (eds.), Sterile Insect Technique - Principles and practice in Area-Wide Integrated Pest Management. Second Edition. CRC Press, Boca Raton, Florida, USA.

Itard, J., D. Cuisance, and G. Tacher. 2003. Trypanosomoses: Historique - répartition géographique, pp. 1607-1615. In P.-C. Lefèvre, J. Blancou, and R. Chermette (eds.), Principales maladies infectieuses et parasitaires du bétail. Europe et Régions Chaudes, Vol. 2. Lavoisier, Paris, France.

Knipling, E. F. 1955. Possibilities of insect population control through the use of sexually sterile males. Journal of Economic Entomology 48: 443-448.

Laveissière, C., and P. Grébaut. 1990. Recherches sur les pièges à glossines (Diptera, Glossinidae). Mise au point d'un modèle économique: Le piège "Vavoua". Tropical Medicine and Parasitology 41: 185192.

Laveissière, C., D. Couret, and T. Traoré. 1985. Tests d'efficacité et de rémanence d'insecticides utilisés en imprégnation sur tissus pour la lutte par piégeage contre les glossines. 1. Protocole experimental, l'effet "knock-down" des pyréthrynoïdes. Cah. ORSTOM Sér. Ent. Méd. et Parasitol. 23: 61-67.

Leak, S. G. A., D. Ejigu, and M. J. B. Vreysen. 2008. Collection of entomological baseline data for tsetse Area-Wide Integrated Pest Management projects. FAO Animal Production and Health Guidelines, Food and Agriculture Organization of the United Nations, Rome, Italy. 215 pp.

Morel, P. C., and S. Touré. 1967. Glossina palpalis gambiensis Vanderplank 1949 (Diptera) dans la région des Niayes et sur la Petite Côte (République du Sénégal). Revue d'Elevage et de Médecine Véterinaire des Pays Tropicaux 20: 571-578.

Mubarqui, R. L., R. C. Perez, R. Angulo Kladt, J. L. Zavala Lopez, A. Parker, M. T. Seck, B. Sall, and J. Bouyer. 2014. The smart aerial release machine, a universal system for applying the Sterile Insect Technique. PLoS One 9: e103077.

Mutika, G. N., I. Kabore, A. G. Parker, and M. J. B. Vreysen. 2014. Storage of male Glossina palpalis gambiensis pupae at low temperature: Effect on emergence, mating and survival. Parasites \& Vectors 7: 465 .

Mutika, G. N., I. Kabore, M. T. Seck, B. Sall, J. Bouyer, A. G. Parker, and M. J. B. Vreysen. 2013. Mating performance of Glossina palpalis gambiensis strains from Burkina Faso, Mali and Senegal. Entomologia Experimentalis et Applicata 146: 177-185.

Pagabeleguem, S., M. T. Seck, B. Sall, M. J. B. Vreysen, G. Gimonneau, A. G. Fall, M. Bassene, I. Sidibé, J. B. Rayaisse, A. Belem, and J. Bouyer. 2015. Long distance transport of irradiated male Glossina palpalis gambiensis pupae and its impact on sterile male yield. Parasites \& Vectors 8: 259.

Pagabeleguem, S., G. Gimonneau, M. T. Seck, M. J. B. Vreysen, B. Sall, J.-B. Rayaissé, I. Sidibé, J. Bouyer, and S. Ravel. 2016a. A molecular method to discriminate between sterile and wild tsetse flies during eradication projects that have a Sterile Insect Technique component. PLoS Neglected Tropical Diseases 10: e0004491.

Pagabeleguem, S., S. Ravel, A. H. Dicko, M. J. B. Vreysen, A. Parker, P. Taback, K. Huber, G. Gimonneau, and J. Bouyer. 2016b. The influence of temperature and relative humidity on survival and fecundity of three Glossina palpalis gambiensis strains. Parasites \& Vectors 9: 520.

(PATTEC) Pan African Tsetse and Trypanosomosis Eradication Campaign. 2019.

Pinchbeck, G. L., L. J. Morrison, A. Tait, J. Langford, L. Meehan, S. Jallow, J. Jallow, A. Jallow, and R. M. Christley. 2008. Trypanosomosis in the Gambia: Prevalence in working horses and donkeys detected by whole genome amplification and PCR, and evidence for interactions between trypanosome species. BMC Veterinary Research 4: 7.

Politzar, H., and D. Cuisance. 1984. An integrated campaign against riverine tsetse flies Glossina palpalis gambiensis and Glossina tachinoides by trapping and the release of sterile males. Insect Science and its Application 5: 439-442.

Projet de Lutte contre la Mouche Tsé-tsé dans le Niayes. 2019. Statistiques. Dakar, Senegal. 
Seck, M. T., J. Bouyer, B. Sall, Z. Bengaly, and M. J. B. Vreysen. 2010. The prevalence of African animal trypanosomoses and tsetse presence in Western Senegal. Parasite 17: 257-265.

Seck, M. T., S. Pagabeleguem, M. D. Bassene, A. G. Fall, T. A. R. Diouf, B. Sall, M. J. B. Vreysen, J.B. Rayaissé, P. Takac, I. Sidibé, A. G. Parker, G. N. Mutika, J. Bouyer, and G. Gimonneau. 2015. Quality of sterile male tsetse after long distance transport as chilled, irradiated pupae. PLoS Neglected Tropical Diseases 9: e0004229.

Solano, P., D. Kaba, S. Ravel, N. Dyer, B. Sall, M. J. B. Vreysen, M. T. Seck, H. Darbyshir, L. Gardes, M. J. Donnelly, T. de Meeûs, and J. Bouyer. 2010. Tsetse population genetics as a tool to choose between suppression and elimination: The case of the Niayes area in Senegal. PLoS Neglected Tropical Diseases 4: e692.

Somda, M. B., Z. Bengaly, E. Dama, A. Poinsignon, G.-K. Dayo, I. Sidibé, F. Remoué, A. Sanon, and B. Bucheton. 2013. First insights into the cattle serological response to tsetse salivary antigens: A promising direct biomarker of exposure to tsetse bites. Veterinary Parasitology 197: 332-340.

Somda, M. B., S. Cornelie, Z. Bengaly, F. Mathieu-Daudé, A. Poinsignon, E. Dama, J. Bouyer, I. Sidibé, E. Demettre, and M. Seveno. 2016. Identification of a Tsal1 $1_{52-75}$ salivary synthetic peptide to monitor cattle exposure to tsetse flies. Parasites \& Vectors 9: 149.

Sow, A., I. Sidibé, Z. Bengaly, Z. Bancé, G. J. Sawadogo, P. Solano, M. J. B. Vreysen, R. Lancelot, and J. Bouyer. 2012. Irradiated male Glossina palpalis gambiensis (Diptera: Glossinidae) from a 40years old colony are still competitive in a riparian forest in Burkina Faso. PLoS One 7: e37124.

Touré, S. 1971. Les glossines (Diptera, Glossinidae) du Sénégal: Ecologie, répartition géographique et incidence sur les trypanosomoses. Revue d'Elevage et de Médecine Véterinaire des Pays Tropicaux 24: 551-563.

Touré, S. 1973. Lutte contre Glossina palpalis gambiensis dans la région des Niayes du Sénégal. Revue d'Elevage et de Médecine Véterinaire des Pays Tropicaux 26: 339-347.

Touré, S. 1974. Note sur quelques particularités dans l'habitat de Glossina palpalis gambiensis Vanderplank, 1949 (Diptera, Glossinidae) observées au Sénégal. Revue d'Elevage et de Médecine Véterinaire des Pays Tropicaux 27: 81-94.

Van der Vloedt, A. M. V., and H. Barnor. 1984. Effects of ionizing radiation on tsetse biology. Their relevance to entomological monitoring during integrated control projects using the Sterile Insect Technique. International Journal of Tropical Insect Science 5: 431-437.

Vreysen, M. J. B. 1995. Radiation induced sterility to control tsetse flies: The effect of ionising radiation and hybridisation on tsetse biology and the use of the Sterile Insect Technique in integrated tsetse control. PhD thesis, Landbouwuniversiteit te Wageningen, The Netherlands.

Vreysen, M. J. B. 2021. Monitoring sterile and wild insects in Area-Wide Integrated Pest Management programmes, pp. 485-528. In V. A. Dyck, J. Hendrichs, and A. S. Robinson (eds.), Sterile Insect Technique - Principles and practice in Area-Wide Integrated Pest Management. Second Edition. CRC Press, Boca Raton, Florida, USA.

Vreysen, M., and A. S. Robinson. 2011. Ionising radiation and area-wide management of insect pests to promote sustainable agriculture. A review. Agronomy for Sustainable Development 2: 671-692.

Vreysen, M. J. B., A. M. V. Van der Vloedt, and H. Barnor. 1996. Comparative gamma radiation sensitivity of G. tachinoides Westw., G. f. fuscipes Newst., and G. brevipalpis Newst. International Journal of Radiation Biology 69: 67-74.

Vreysen, M., A. S. Robinson, and J. Hendrichs (eds.). 2007. Area-wide control of insect pests. From research to field implementation. Springer, Dordrecht, The Netherlands. 789 pp.

Vreysen, M. J. B., M. T. Seck, B. Sall, and J. Bouyer. 2013. Tsetse flies: Their biology and control using Area-Wide Integrated Pest Management approaches. Journal of Invertebrate Pathology 112: S15-S25.

Vreysen, M. J. B., K. M. Saleh, M. Y. Ali, A. M. Abdulla, Z.-R. Zhu, K. G. Juma, V. A. Dyck, A. R. Msangi, P. A. Mkonyi, and H. U. Feldmann. 2000. Glossina austeni (Diptera: Glossinidae) eradicated on the island of Unguja, Zanzibar, using the Sterile Insect Technique. Journal of Economic Entomology 93: 123-135.

Vreysen, M. J. B., K. Saleh, F. Mramba, A. Parker, U. Feldmann, V. A. Dyck, A. Msangi, and J. Bouyer. 2014. Sterile insects to enhance agricultural development: The case of sustainable tsetse eradication on Unguja island, Zanzibar using an Area-Wide Integrated Pest Management approach. PLoS Neglected Tropical Diseases 8: e2857.

Wikipedia. 2019. Autogyro. Principle of operation. 